\title{
High-performance photovoltaic perovskite layers fabricated through intramolecular exchange
}

\section{Woon Seok Yang, ${ }^{*}$ Jun Hong Noh, ${ }^{1 *}$ Nam Joong Jeon, ${ }^{1}$ Young Chan Kim, ${ }^{1}$ Seungchan Ryu, ${ }^{1}$ Jangwon Seo, ${ }^{1}$ Sang II Seok ${ }^{1,2} \uparrow$}

'Division of Advanced Materials, Korea Research Institute of Chemical Technology, 141 Gajeong-Ro, Yuseong-Gu, Daejeon 305-600, Korea. ${ }^{2}$ Department of Energy Science, Sungkyunkwan University, Suwon 440-746, Republic of Korea. †Corresponding author. E-mail: seoksi@krict.re.kr (seoksi@skku.edu)

*These authors contributed equally to this work.

The band gap of formamidinium lead iodide $\left(\mathrm{FAPbl}_{3}\right)$ perovskites allows broader absorption of the solar spectrum compared to conventional methylammonium lead iodide $\left(\mathrm{MAPbl}_{3}\right)$. The optoelectronic properties of perovskite films are closely related to the film-quality, so depositing dense and uniform films is crucial for fabricating high-performance perovskite solar cells (PSCs). We report an approach for depositing high-quality $\mathrm{FAPbl}_{3}$ films, involving $\mathrm{FAPbl}_{3}$ crystallization by the direct intramolecular exchange of dimethylsulfoxide (DMSO) molecules intercalated in $\mathrm{Pbl}_{2}$ with formamidinium iodide. This process produces $\mathrm{FAPbl}_{3}$ films with (111)preferred crystallographic orientation, large-grained dense microstructures, and flat surfaces without residual $\mathrm{Pbl}_{2}$. Using films prepared by this technique, $\mathrm{FAPbl}_{3}$-based PSCs with maximum power conversion efficiency of over $20 \%$ were fabricated.

The tremendous improvements in device architecture (1-3), high-quality film formation methodologies (4-6), and compositional engineering of perovskite materials (7-9) over the last 3 years have led to rapid improvements in the power conversion efficiency (PCE) of perovskite solar cells (PSCs). Although solar-to-electric PCE of up to $18 \%$ has been reported for PSCs (10), developing technologies further to achieve PCEs near theoretical values continues to be among the most important challenges in the solar cell industry to achieve economic feasibility.

Formamidinium lead iodide $\left(\mathrm{FAPbI}_{3}\right)$ is a perovskite material that can potentially provide better performance than methylammonium lead iodide $\left(\mathrm{MAPbI}_{3}\right)$ because of its broad absorption of the solar spectrum. In addition, $\mathrm{FAPbI}_{3}$ with the n-i-p architecture (the n-side is illuminated with solar radiation) exhibits negligible hysteresis with sweep direction during current-voltage measurements (8-13). However, compared to $\mathrm{MAPbI}_{3}$, it is more difficult to form stable perovskite phases and high-quality films of $\mathrm{FAPbI}_{3}$. Various methodologies such as sequential deposition (4), solventengineering (5), vapor-assisted deposition (14), additiveassisted deposition $(15,16)$, and vacuum evaporation (6) can now produce high-quality films of $\mathrm{MAPbI}_{3}$ with flat surfaces and complete surface coverage by controlling its rapid crystallization behavior and have led to substantial improve- ments in the PCE of $\mathrm{MAPbI}_{3}{ }^{-}$ based PSCs.

Among these methodologies, two-step sequential deposition and solvent-engineering are representative wet processes that can yield perovskite films for high-performance PSCs. In the sequential deposition process, a thin layer of $\mathrm{PbI}_{2}$ is deposited on the substrate. methylammonium iodide (MAI) or formamidinium iodide (FAI) is then applied to the pre-deposited $\mathrm{PbI}_{2}$ to enable conversion to the perovskite phase. This process involves crystal nucleation and growth of the perovskite phase because of solution-phase or solid-state reaction between $\mathrm{PbI}_{2}$ and an organic iodide such as MAI or FAI $(4,13,17)$. However, the sequential reaction of organic iodides with $\mathrm{PbI}_{2}$ that occurs from the surface to the inner crystalline regions of $\mathrm{PbI}_{2}$ has been ineffective in producing highperformance perovskite films that are $>500 \mathrm{~nm}$ in thickness because of incomplete conversion of $\mathrm{PbI}_{2}$, peeling-off of the perovskite film in solution, and uncontrolled surface roughness. In contrast, the solvent-engineering process utilizes the formation of intermediate phases to retard the rapid reaction between $\mathrm{PbI}_{2}$ and organic iodide in the solution. While this process has been successfully used to form dense and uniform $\mathrm{MAPbI}_{3}$ layers, it has not been explored for $\mathrm{FAPbI}_{3}(5)$.

To deposit a uniform and dense $\mathrm{FAPbI}_{3}$ layer, Snaith et al. added a small amount of aqueous HI to a solution mixture containing $\mathrm{PbI}_{2}, \mathrm{FAI}$, and dimethylformamide (DMF) (11). Very recently, Zhao et al. reported the deposition of highly uniform and fully covered $\mathrm{FAPbI}_{3}$ films using FAI and $\mathrm{HPbI}_{3}$, which is formed by the reaction of $\mathrm{PbI}_{2}$ and $\mathrm{HI}$ in DMF (18). The HI in the $\mathrm{PbI}_{2}$ layers retards the rapid reaction between FAI and $\mathrm{PbI}_{2}$. In addition, the release of $\mathrm{HI}$ from $\mathrm{PbI}_{2}$ at high temperatures allows the formation of a $\mathrm{FAPbI}_{3}$ layer by solid-state reaction with the neighboring FAI molecules. Stated differently, this process can be regarded as the transformation of $\mathrm{PbI}_{2}$-HI-FAI into $\mathrm{FAPbI}_{3}$, similar to the formation of $\mathrm{MAPbI}_{3}$ via the $\mathrm{PbI}_{2-}$ dimethylsulfoxide (DMSO)-MAI phase in the solventengineering process (5).

However, we observed that the solvent-engineering process, which is effective for depositing dense and uniform $\mathrm{MAPbI}_{3}$ layers, yields $\mathrm{FAPbI}_{3}$ layers with pin-holes and a 
rough surface. Although the $\mathrm{FAPbI}_{3}$ film-quality including coverage and uniformity on the substrate have been improved, the performance of $\mathrm{FAPbI}_{3}$-solar cells still lag behind those of $\mathrm{MAPbI}_{3}$-based PSC (8), implying that more sophisticated deposition techniques are necessary for fabricating high-quality, thick $\mathrm{FAPbI}_{3}$ films (> $500 \mathrm{~nm}$ ), for achieving sufficient absorption up to a wavelength of 840 nm.

As expected from the conversion of $\mathrm{PbI}_{2}$-DMSO-MAI to $\mathrm{MAPbI}_{3}(5)$, the $\mathrm{DMSO}$ molecules intercalated in $\mathrm{PbI}_{2}$ can be easily replaced by external FAIs because of its higher affinity toward $\mathrm{PbI}_{2}$ compared to DMSO; the FAI molecules experience ionic interactions, whereas DMSO participates in van der Waals interactions $(5,19)$. Highly uniform and dense pre-deposited $\mathrm{PbI}_{2}$-(DMSO) layers could be directly converted to $\mathrm{FAPbI}_{3}$ because the inorganic $\mathrm{PbI}_{2}$ framework would be retained. $\mathrm{FAPbI}_{3}$ crystallization by the intramolecular exchange process (IEP) of DMSO intercalated in $\mathrm{PbI}_{2}$ with FAI was schematically shown in Fig. 1A. The intramolecular exchange between DMSO and FAI can be described as

$\mathrm{PbI}_{2}-\mathrm{DMSO}+\mathrm{FAI} \rightarrow \mathrm{PbI}_{2}-\mathrm{FAI}+\mathrm{DMSO} \uparrow($ removal $)(1)$

and does not induce volume expansion, unlike the FAP$\mathrm{bI}_{3}$ formed with FAI intercalating into pristine $\mathrm{PbI}_{2}$ (discussed below) because the molecular sizes of DMSO and FAI are similar.

In this work, we report on the synthesis of a $\mathrm{PbI}_{2}$ (DMSO) precursor with excellent capabilities for molecular exchange with FAI at low temperatures during the spinning process, as well as the fabrication of highly efficient $\mathrm{FAPbI}_{3}$ based PSCs with certified PCEs exceeding 20\%. To synthesize the $\mathrm{PbI}_{2}$-(DMSO) precursors, precipitates were obtained by pouring toluene as a non-solvent into $1.0 \mathrm{M} \mathrm{PbI}_{2}$ solution dissolved in DMSO. The x-ray diffraction (XRD) pattern of the resulting complex (Fig. 1Ba) matched that of the $\mathrm{PbI}_{2}(\mathrm{DMSO})_{2}$ phase $(5,19)$. The as-prepared $\mathrm{PbI}_{2}(\mathrm{DMSO})_{2}$ was then annealed at $60^{\circ} \mathrm{C}$ for 24 hours in vacuum to obtain $\mathrm{PbI}_{2}$ (DMSO) by removal of $1 \mathrm{~mol}$ DMSO. The XRD pattern of the vacuum-annealed powder (Fig. $1 \mathrm{Bb}$ ) did not match that of $\mathrm{PbI}_{2}(\mathrm{DMSO})_{2}$, implying that the $\mathrm{PbI}_{2}(\mathrm{DMSO})_{2}$ transformed into a different phase by releasing some DMSO molecules. The content of DMSO in the as-annealed powder was estimated by thermogravimetric analysis (TGA). TGA was suitable for this purpose because the only volatile species in the powder was DMSO. The TGA results of the $\mathrm{PbI}_{2}(\mathrm{DMSO})_{2}$ and $\mathrm{PbI}_{2}(\mathrm{DMSO})$ complexes are shown in Fig. 1C. The $\mathrm{PbI}_{2}(\mathrm{DMSO})_{2}$ complex exhibited a two-step decomposition process with weight-loss of $12.6 \%$ at each step, whereas the vacuum-annealed $\mathrm{PbI}_{2}(\mathrm{DMSO})$ complex showed a singlestep decomposition. The decomposition of both the complexes was completed at the same temperature $\left(138.6^{\circ} \mathrm{C}\right)$. The powders obtained by vacuum-annealing $\mathrm{PbI}_{2}(\mathrm{DMSO})_{2}$ complex at $60^{\circ} \mathrm{C}$ can be regarded as one of the most thermodynamically stable forms among the various crystalline $\mathrm{PbI}_{2}$-(DMSO)-based complexes, which are similar with $\mathrm{PbBr}_{2}$ (DMSO) and $\mathrm{PbCl}_{2}(\mathrm{DMSO})$ (20). The DMSO content of the vacuum-annealed $\mathrm{PbI}_{2}(\mathrm{DMSO})$ complex was also checked by elemental analysis (EA), which yielded $\mathrm{H}=1.0 \%$ (1.1\%); and $\mathrm{C}=4.1 \%$ (4.4\%), where the values expressed in parenthesis indicate the theoretical mass percent for a given element for $\mathrm{C}_{2} \mathrm{H}_{6} \mathrm{SOPbI}_{2}$.

To fabricate $\mathrm{FAPbI}_{3}$-based PSCs through IEP between DMSO and FAI (MABr) using pre-deposited $\mathrm{PbI}_{2}$-DMSO layers and a FAI (MABr) solution, we first confirmed that the $\mathrm{PbI}_{2}(\mathrm{DMSO})$ phase was retained even after spin-coating with the $\mathrm{PbI}_{2}(\mathrm{DMSO})$ precursor dissolved in DMF. The XRD pattern for film coated on a fused silica substrate was compared with that of the initial precursor. As seen in Fig. 1Bc, the XRD pattern for the as-coated film was in consistent with that of the $\mathrm{PbI}_{2}(\mathrm{DMSO})$ complex powder, although its crystallinity is lowered. The as-coated $\mathrm{PbI}_{2}$ (DMSO) film also had a flat and dense surface, as shown in the field-emission scanning electron microscopy (FESEM) image in fig. S1 (21). Next, we investigated the formation of mixed FAP$\mathrm{bI}_{3} / \mathrm{MAPbBr}_{3}$ by IEP. We recently reported that the coexistence of $\mathrm{MA} / \mathrm{FA} / \mathrm{I} / \mathrm{Br}$ in the $\mathrm{PbI}_{2}$ skeleton improved the phase-stability of $\mathrm{FAPbI}_{3}(10)$. The formation of mixed FAP$\mathrm{bI}_{3} / \mathrm{MAPbBr}_{3}$ layers via IEP was controlled by coating solution mixture with different mole ratios of MABr to FAI dissolved in isopropyl alcohol (IPA), on the pre-deposited $\mathrm{PbI}_{2}$ (DMSO) layers (discussed below). It is evident from Fig. 1Da that well-crystallized $\mathrm{FAPbI}_{3}$-based films were formed by IEP. The XRD pattern for the $\mathrm{FAPbI}_{3}$ film derived from the $\mathrm{PbI}_{2}(\mathrm{DMSO})$ complex film exhibits dominant (-111) and (-222) diffraction peaks at $13.9^{\circ}$ and $28.1^{\circ}$, respectively, corresponding to the $\mathrm{FAPbI}_{3}$ trigonal perovskite phase (P3m1), in contrast with the XRD patterns of the $\mathrm{FAPbI}_{3}$ powder (Fig. 1Db) (13). The intensity ratio of (-123) peak at $31.5^{\circ}$ to the $(-222)$ peak at $28.1^{\circ}$ was 0.05 . This value was much smaller than the corresponding intensity ratios $(=0.8)$ for the $\mathrm{FAPbI}_{3}$ power. Thus, IEP leads to high-quality pure $\mathrm{FAPbI}_{3}$-based films with preferred orientation along the [111] axis.

Fig. S2 (21) presents the current density-voltage $(J-V)$ curves measured under standard air-mass 1.5 global (AM 1.5G) illumination, and the external quantum efficiency (EQE) spectra of the fabricated cells with $\mathrm{FAPbI}_{3}$-based layers fabricated with various amounts of MABr ( 0 to 20 mol\%). The onset wavelength in the EQE spectra near 830 $\mathrm{nm}$ showed a non-linear blue shift with increasing amounts of $\mathrm{MABr}$, indicating that there is unsymmetrical competition between $\mathrm{FAI}$ and $\mathrm{MABr}$ in forming the $\mathrm{FAPbI}_{3}$ $\mathrm{MAPbBr}_{3}$ perovskite phase through an intramolecular exchange reaction. Nevertheless, the highest PCE of $19.2 \%$ was achieved for the film fabricated from a FAI solution containing $15 \mathrm{~mol} \% \mathrm{MABr}$. To accurately determine the composition of the $\mathrm{FAPbI}_{3}$-based layer, we investigated the lattice parameter using XRD and the band gap using the EQE for the film showing the best performance. Fig. S3 (21) shows the pseudocubic lattice parameter for $\left(\mathrm{FAPbI}_{3}\right)_{1-\mathrm{x}}\left(\mathrm{MAPbBr}_{3}\right)_{\mathrm{x}}$ as a function of $x$, in which the composition was controlled 
by a previously reported method (10). In this study, the pseudocubic lattice parameter of the $\mathrm{FAPbI}_{3} / \mathrm{MAPbBr}_{3}$ film fabricated by IEP with a FAI solution containing $15 \mathrm{~mol} \%$ $\mathrm{MABr}$ is $6.348 \AA$ A. As indicated in fig. S4 (21), the lattice parameter can be assigned as $x=\sim 5$, corresponding to (FAP$\left.\mathrm{bI}_{3}\right)_{0.95}\left(\mathrm{MAPbBr}_{3}\right)_{0.05}$. This result is in agreement with the value estimated using the band gap $(1.49 \mathrm{eV})$ from EQE [fig. S3 (21)], because pure $\mathrm{FAPbI}_{3}$ has a band gap of $1.47 \mathrm{eV}$ and $\left(\mathrm{FAPbI}_{3}\right)_{0.85}\left(\mathrm{MAPbBr}_{3}\right)_{0.15}, 1.55 \mathrm{eV}$ (10). Fortunately, the simultaneous introduction of both $\mathrm{MA}^{+}$cations and $\mathrm{Br}^{-}$anions in $\mathrm{FAPbI}_{3}$ even after incorporating $5 \mathrm{~mol} \%$ of $\mathrm{MAPbBr}_{3}$ serves to stabilize the perovskite phase (10).

After comparing the absorption coefficients of $\mathrm{FAPbI}_{3}$ and $\mathrm{MAPbI}_{3}$ at wavelengths beyond $800 \mathrm{~nm}$, we noted that the thickness of a $\mathrm{FAPbI}_{3}$ layer needed to be higher than the optimal thickness of a typical perovskite layer with a band gap of $\sim 1.55 \mathrm{eV}$ (300 to $400 \mathrm{~nm}$ ) to guarantee fully lightharvesting around $800 \mathrm{~nm}(20,22)$. We deposited $\mathrm{FAPbI}_{3}-$ based layers with thickness of $\sim 500 \mathrm{~nm}$, and fabricated devices consisting of fluorine-doped tin oxide (FTO)glass/barrier layer (bl)- $\mathrm{TiO}_{2} /$ mesoporous (mp)$\mathrm{TiO}_{2} /$ perovskite/poly-triarylamine (PTAA)/Au (n-i-p architecture), as shown in the cross-sectional FESEM image of Fig. 2A. FESEM plane-view images of the device with film derived from $\mathrm{PbI}_{2}(\mathrm{DMSO})$ complex and $\mathrm{PbI}_{2}$ films are shown in Fig. 2B. The $\mathrm{FAPbI}_{3}$ film derived from $\mathrm{PbI}_{2}(\mathrm{DMSO})$ exhibited a dense and well-developed grain structure with larger grains than the $\mathrm{FAPbI}_{3}$ film derived from $\mathrm{PbI}_{2}$. Figure 2Ca shows the $J-V$ curves measured via reverse and forward bias sweep for one of the best-performing solar cell. The devices we fabricated also showed no hysteresis. Here, we believe that the hysteresis is highly dependent on the perovskite materials $\left(\mathrm{FAPbI}_{3}\right.$ or $\left.\mathrm{MAPbI}_{3}\right)$ and cell architecture (n-i-p or $\mathrm{p}$-i-n), although the ferroelectric properties of the perovskite itself are more likely to be the origin of the hysteresis in PSCs $(23,24)$. Thus, $\mathrm{FAPbI}_{3}$-based PSCs with n-i-p architecture show negligible hysteresis between the reverse and the forward scan in the I-V characteristics. In contrast, $\mathrm{FAPbI}_{3}$ based cells consisting of $\mathrm{FTO} / \mathrm{NIO} /$ perovskite/PCBM/LiF/Al (p-i-n architecture) showed very strong hysteresis [fig. S4 (21)]. $J_{\mathrm{SC}}, V_{\mathrm{OC}}$, and $F F$ determined from the $J-V$ curves were $24.7 \mathrm{~mA} \mathrm{~cm}{ }^{-2}, 1.06 \mathrm{~V}$, and $77.5 \%$, respectively, and correspond to a PCE of $20.2 \%$ under standard AM 1.5G illumination. Figure $2 \mathrm{Cb}$ shows the EQE spectrum and integrated $J_{\mathrm{SC}}$ for one of the best-performing solar cell. The high $J_{\mathrm{SC}}$ is attributed to a very broad EQE plateau of $>85 \%$ in the illumination wavelength range of 400 to $780 \mathrm{~nm}$ and broad lightharvesting up to a long wavelength of $840 \mathrm{~nm}$, owing to the relatively low band gap $(1.47 \mathrm{eV})$ of $\mathrm{FAPbI}_{3}$. The $J_{\mathrm{SC}}$ value $\left(24.4 \mathrm{~mA} \mathrm{~cm}^{-2}\right)$ obtained by integrating $\mathrm{EQE}$ spectrum agreed well with that derived from the $J-V$ measurement. The PCE of the best-performing cell (20.2\%) was certified by the standardized method in the PV calibration laboratory, which confirmed a PCE of $20.1 \%$ under AM 1.5 G full-sun illuminations [fig. S5 (21)].
To gain more insight into the enhanced performance of the $\mathrm{FAPbI}_{3}$-based PSCs, we compared the properties of the films fabricated by IEP with those obtained from a conventional sequential process. A sequential reaction such as inter-diffusion between FAI/MAI and $\mathrm{PbI}_{2}$ through thermal annealing in organic iodide/ $\mathrm{PbI}_{2}$ multilayer films has been used to form perovskite $\mathrm{FAPbI}_{3} / \mathrm{MAPbI}_{3}$ films from inorganic $\mathrm{PbI}_{2}$ films in the conventional process (17). Thus, considerable volume expansion occurs in the sequential deposition process based on $\mathrm{PbI}_{2}$ because of the growth of perovskite crystals with the insertion of organic iodides into $\mathrm{PbI}_{2}$ skeleton $(14,22)$. As expected, an initial $\mathrm{PbI}_{2}$ film with thickness of $\sim 290 \mathrm{~nm}$ was doubled to $570 \mathrm{~nm}$ for the film formed by the reaction of $\mathrm{PbI}_{2}$ with FAI [Table 1 and fig. S6 (21)].

In contrast, the change in thickness observed by the application of the FAI (MABr) solution to the pre-deposited $\mathrm{PbI}_{2}$-(DMSO) film was negligible. In fact, the reaction between FAI (MABr) and $\mathrm{PbI}_{2}$ (DMSO) was completed within 1 min during spin-coating and the $\mathrm{FAPbI}_{3}$ perovskite phase was formed without sequential annealing. However, in a conventional process using $\mathrm{PbI}_{2}$ films, annealing at high temperature is required to achieve interdiffusion. Figure 3A compares XRD patterns for as-formed and annealed films by IEP and conventional process from $\mathrm{PbI}_{2}(\mathrm{DMSO})$ complex film and $\mathrm{PbI}_{2}$ film, respectively; there is no appreciable difference in XRD patterns between as-formed and annealed film. This result confirms that the $\mathrm{FAPbI}_{3}$-based layer is formed by the IEP of DMSO and FAI (MABr) without additional annealing process. In addition, such an exchange can considerably favor crystallization into perovskite, compared to conventional interdiffusion from $\mathrm{PbI}_{2}$, and led to an increase in the XRD peaks intensity after annealing at $150^{\circ} \mathrm{C}$ for $20 \mathrm{~min}$. However, the as-formed film with $\mathrm{PbI}_{2}$ showed $\mathrm{XRD}$ patterns assigned to $\mathrm{PbI}_{2}, \mathrm{FAI}$, and $\mathrm{FAPbI}_{3}$, and a (002) peak at $12.5^{\circ}$ corresponding to the $\mathrm{PbI}_{2}$ still remains after annealing at same temperature and time with IEP. In particular, the $\mathrm{FAPbI}_{3}$ film prepared by IEP is remarkably preferred (111)-oriented compared to $\mathrm{FAPbI}_{3}$ film annealed after preparing it by conventional process.

The advantages of IEP become further apparent upon comparing the $J-V$ curves and PCEs of $\mathrm{FAPbI}_{3}$-based devices derived from $\mathrm{PbI}_{2}(\mathrm{DMSO})$ complex films and conventional $\mathrm{PbI}_{2}$ films (Fig. 3, B and C). The devices based on $\mathrm{FAPbI}_{3}$ fabricated from $\mathrm{PbI}_{2}(\mathrm{DMSO})$ showed superior PCEs with smaller deviations in the value, compared to those prepared from conventional $\mathrm{PbI}_{2}$ films. High-efficiency solar cells with average PCEs of over $19 \%$ could be produced with a high degree of reproducibility by using the IEP. This study provides an effective protocol for fabricating efficient and cost-effective inorganic-organic hybrid heterojunction solar cells.

\section{REFERENCES AND NOTES}

1. J. H. Heo, S. H. Im, J. H. Noh, T. N. Mandal, C.-S. Lim, J. A. Chang, Y. H. Lee, H.- 
Kim, A. Sarkar, M. K. Nazeeruddin, M. Grätzel, S. I. Seok, Efficient inorganicorganic hybrid heterojunction solar cells containing perovskite compound and polymeric hole conductors. Nat. Photonics 7, 486-491 (2013). doi:10.1038/nphoton.2013.80

2. H.-S. Kim, C.-R. Lee, J.-H. Im, H.-S. Kim, H.-S. Kim, H.-S. Kim, Lead iodide perovskite sensitized all-solid-state submicron thin film mesoscopic solar cell with efficiency exceeding 9\%. Sci. Rep. 2, 591 (2012).

3. M. M. Lee, J. Teuscher, T. Miyasaka, T. N. Murakami, H. J. Snaith, Efficient hybrid solar cells based on meso-superstructured organometal halide perovskites. Science 338, 643-647 (2012). Medline doi:10.1126/science.1228604

4. J. Burschka, N. Pellet, S. J. Moon, R. Humphry-Baker, P. Gao, M. K. Nazeeruddin, M. Grätzel, Sequential deposition as a route to high-performance perovskitesensitized solar cells. Nature 499, 316-319 (2013). Medline doi:10.1038/nature12340

5. N. J. Jeon, J. H. Noh, Y. C. Kim, W. S. Yang, S. Ryu, S. I. Seok, Solvent engineering for high-performance inorganic-organic hybrid perovskite solar cells. Nat. Mater. 13, 897-903 (2014). Medline doi:10.1038/nmat4014

6. M. Liu, M. B. Johnston, H. J. Snaith, Efficient planar heterojunction perovskite solar cells by vapour deposition. Nature 501, 395-398 (2013). Medline doi:10.1038/nature12509

7. J. H. Noh, S. H. Im, J. H. Heo, T. N. Mandal, S. I. Seok, Chemical management for colorful, efficient, and stable inorganic-organic hybrid nanostructured solar cells. Nano Lett. 13, 1764-1769 (2013).Medline

8. J. W. Lee, D. J. Seol, A. N. Cho, N. G. Park, High-efficiency perovskite solar cells based on the black polymorph of $\mathrm{HC}\left(\mathrm{NH}_{2}\right)_{2} \mathrm{Pbl}$. Adv. Mater. 26, 4991-4998 (2014). Medline doi:10.1002/adma.201401137

9. N. Pellet, P. Gao, G. Gregori, T.-Y. Yang, M. K. Nazeeruddin, J. Maier, M. Grätzel, Mixed-organic-cation perovskite photovoltaics for enhanced solar-light harvesting. Angew. Chem. Int. Ed. Engl. 53, 3151-3157 (2014). Medline doi:10.1002/anie.201309361

10. N. J. Jeon, J. H. Noh, W. S. Yang, Y. C. Kim, S. Ryu, J. Seo, S. I. Seok, Compositional engineering of perovskite materials for high-performance solar cells. Nature 517, 476-480 (2015). Medline doi:10.1038/nature14133

11. G. E. Eperon, S. D. Stranks, C. Menelaou, M. B. Johnston, L. M. Herz, H. J. Snaith, Formamidinium lead trihalide: A broadly tunable perovskite for efficient planar heterojunction solar cells. Energy Environ. Sci. 7, 982-988 (2014). 10.1039/C3EE43822H doi:10.1039/c3ee43822h

12. T. M. Koh, K. Fu, Y. Fang, S. Chen, T. C. Sum, N. Mathews, S. G. Mhaisalkar, P. P. Boix, T. Baikie, Formamidinium-containing metal-halide: An alternative material for near-IR absorption perovskite solar cells. J. Phys. Chem. C 118, 16458-16462 (2014). doi:10.1021/jp411112k

13. S. Pang, H. Hu, J. Zhang, S. Lv, Y. Yu, F. Wei, T. Qin, H. Xu, Z. Liu, G. Cui, $\mathrm{NH}_{2} \mathrm{CH}=\mathrm{NH}_{2} \mathrm{Pbl}_{3}$ : An alternative organolead iodide perovskite sensitizer for mesoscopic solar cells. Chem. Mater. 26, 1485-1491 (2014). doi:10.1021/cm404006p

14. Q. Chen, H. Zhou, Z. Hong, S. Luo, H. S. Duan, H. H. Wang, Y. Liu, G. Li, Y. Yang, Planar heterojunction perovskite solar cells via vapor-assisted solution process. J. Am. Chem. Soc. 136, 622-625 (2014). Medline doi:10.1021/ja411509g

15. P. W. Liang, C. Y. Liao, C. C. Chueh, F. Zuo, S. T. Williams, X. K. Xin, J. Lin, A. K. Jen, Additive enhanced crystallization of solution-processed perovskite for highly efficient planar-heterojunction solar cells. Adv. Mater. 26, 3748-3754 (2014). Medline doi:10.1002/adma.201400231

16. J. H. Im, I. H. Jang, N. Pellet, M. Grätzel, N. G. Park, Growth of $\mathrm{CH}_{3} \mathrm{NH}_{3} \mathrm{Pbl}{ }_{3}$ cuboids with controlled size for high-efficiency perovskite solar cells. Nat. Nanotechnol. 9, 927-932 (2014). Medline doi:10.1038/nnano.2014.181

17. Y. Wu, A. Islam, X. Yang, C. Qin, J. Liu, K. Zhang, W. Peng, L. Han, Retarding the crystallization of $\mathrm{Pbl}_{2}$ for highly reproducible planar-structured perovskite solar cells via sequential deposition. Energy Environ. Sci. 7, 2934-2938 (2014).

\section{doi:10.1039/C4EE01624F}

18. F. Wang, H. Yu, H. Xu, N. Zhao, HPbl: A new precursor compound for highly efficient solution-processed perovskite solar cells. Adv. Funct. Mater. 25, 11201126 (2015). doi:10.1002/adfm.201404007

19. H. Miyamae, Y. Numahata, M. Nagata, The crystal structure of lead(II) iodidedimethylsulphoxide(1/2), $\mathrm{Pbl}_{2}(\mathrm{dms0})_{2}$. Chem. Lett. 9, 663-664 (1980). doi:10.1246/cl.1980.663

20. J. Selbin, W. Bull, L. Holmes Jr., Metallic complexes of dimethylsulphoxide. J. Inorg. Nucl. Chem. 16, 219-224 (1961). doi:10.1016/0022-1902(61)80493-4

21. See supplementary materials on Science Online.

22. L. Hu, J. Peng, W. Wang, Z. Xia, J. Yuan, J. Lu, X. Huang, W. Ma, H. Song, W. Chen, Y.-B. Cheng, J. Tang, Sequential deposition of $\mathrm{CH}_{3} \mathrm{NH}_{3} \mathrm{Pbl}_{3}$ on planar $\mathrm{NiO}$ film for efficient planar perovskite solar cells. ACS Photonics 1, 547-553 (2014). doi:10.1021/ph5000067

23. H. J. Snaith, A. Abate, J. M. Ball, G. E. Eperon, T. Leijtens, N. K. Noel, S. D. Stranks, J. T.-W. Wang, K. Wojciechowski, W. Zhang, Anomalous hysteresis in perovskite solar cells. J. Phys. Chem. Lett. 5, 1511-1515 (2014) doi:10.1021/jz500113x

24. J. M. Frost, K. T. Butler, F. Brivio, C. H. Hendon, M. van Schilfgaarde, A. Walsh, Atomistic origins of high-performance in hybrid halide perovskite solar cells. Nano Lett. 14, 2584-2590 (2014). Medline doi:10.1021/nl500390f

\section{ACKNOWLEDGMENTS}

This work was supported by the Global Research Laboratory (GRL) Program, the Global Frontier R\&D Program on Center for Multiscale Energy System funded by the National Research Foundation in Korea, and by a grant from the KRICT 2020 Program for Future Technology of the Korea Research Institute of Chemical Technology (KRICT), Republic of Korea.

\section{SUPPLEMENTARY MATERIALS}

www.sciencemag.org/cgi/content/full/science.aaa9272/DC1

Materials and Methods

Figs. S1 to S6

14 February 2015; accepted 30 April 2015

Published online 21 May 2015

10.1126/science.aaa9272 
A

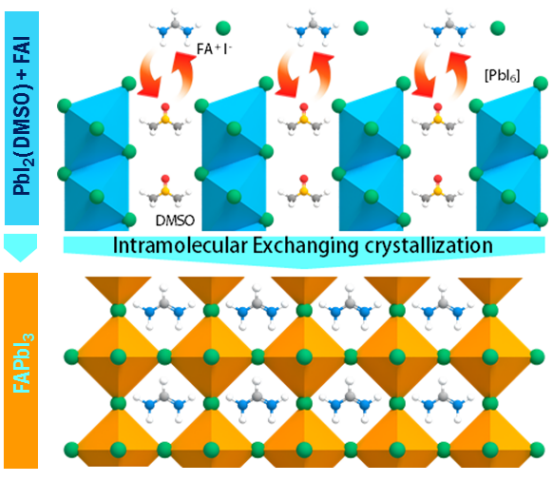

C

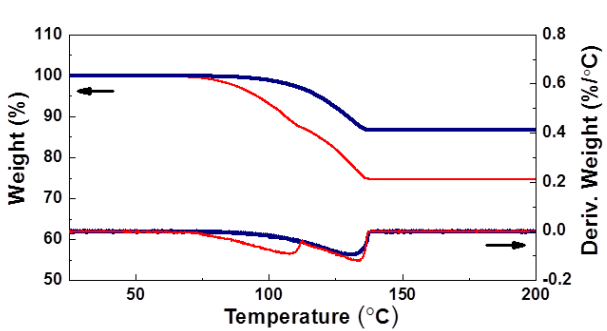

B

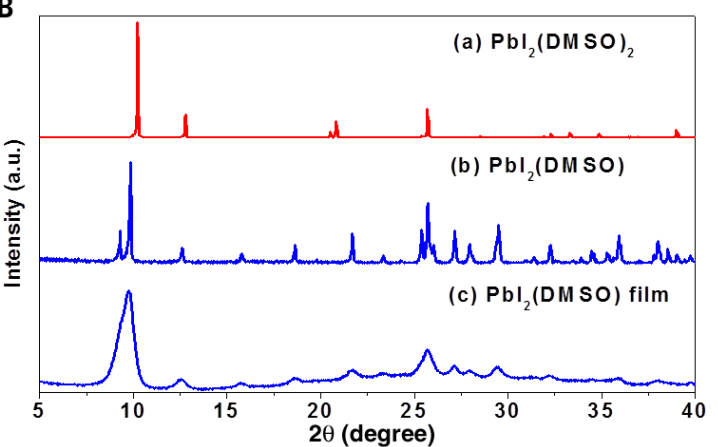

(a) FAPbl, film

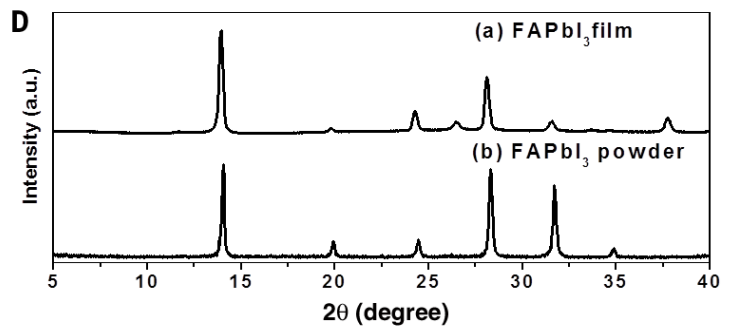

Fig. 1. $\mathrm{Pbl}_{2}$-complex formation and X-ray diffraction. (A) Schematics of $\mathrm{FAPbl}_{3}$ perovskite crystallization involving the direct intramolecular exchange of dimethylsulfoxide (DMSO) molecules intercalated in $\mathrm{Pbl}_{2}$ with formamidinium iodide (FAI). The DMSO molecules are intercalated between edge-sharing $\left[\mathrm{Pbl}_{6}\right]$ octahedral layers. (B) XRD patterns of (a) as-prepared $\mathrm{Pbl}_{2}(\mathrm{DMSO})_{2}$ powders, (b) vacuum-annealed $\mathrm{Pbl}_{2}(\mathrm{DMSO})$ powders, and (c) as-deposited film on fused quartz substrate using $\mathrm{Pbl}_{2}$ (DMSO) complex solution. (C) TGA of $\mathrm{Pbl}_{2}(\mathrm{DMSO})_{2}$ (red line) and $\mathrm{Pbl}_{2}$ (DMSO) (dark blue line). (D) XRD patterns of (a) as-formed film of $\mathrm{FAPbl}_{3}$ by IEP, and (b) $\mathrm{FAPbl}_{3}$ powder. 
A
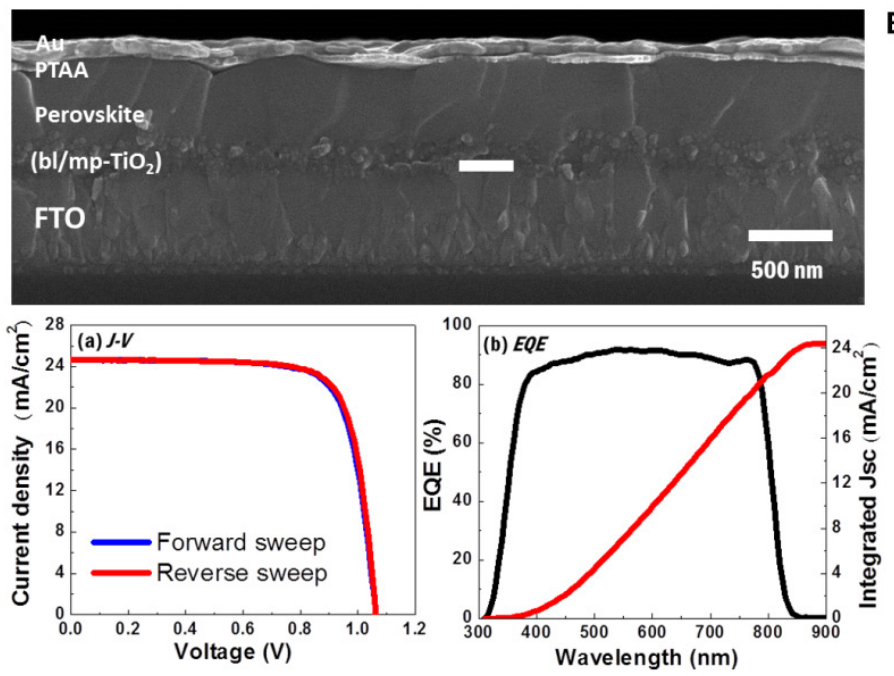

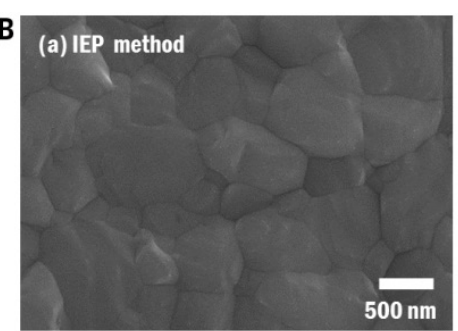

(b) Conventional method

Fig. 2. SEM observation, I-V and EQE measurements. (A) Cross-sectional FESEM image of the device consisting of $\mathrm{FTO}-\mathrm{Glass} / \mathrm{bl}-\mathrm{TiO}_{2} / \mathrm{mp}$ $\mathrm{TiO}_{2} /$ perovskite/PTAA/Au. (B) The comparison of FESEM surface images of $\mathrm{FAPbl}_{3}$-based layer formed on $\mathrm{mp}-\mathrm{TiO}_{2}$ by IEP and conventional method. (C) (a) J$\checkmark$ curves of best device measured with a 40 ms scanning delay in reverse (from 1.2 $\mathrm{V}$ to $\mathrm{O} \mathrm{V}$ ) and forward (from $\mathrm{O} \mathrm{V}$ to $1.2 \mathrm{~V}$ ) modes under standard $\mathrm{AM} 1.5 \mathrm{G}$ illumination, and (b) EQE spectra for best device and integrated $J_{S C}$ 

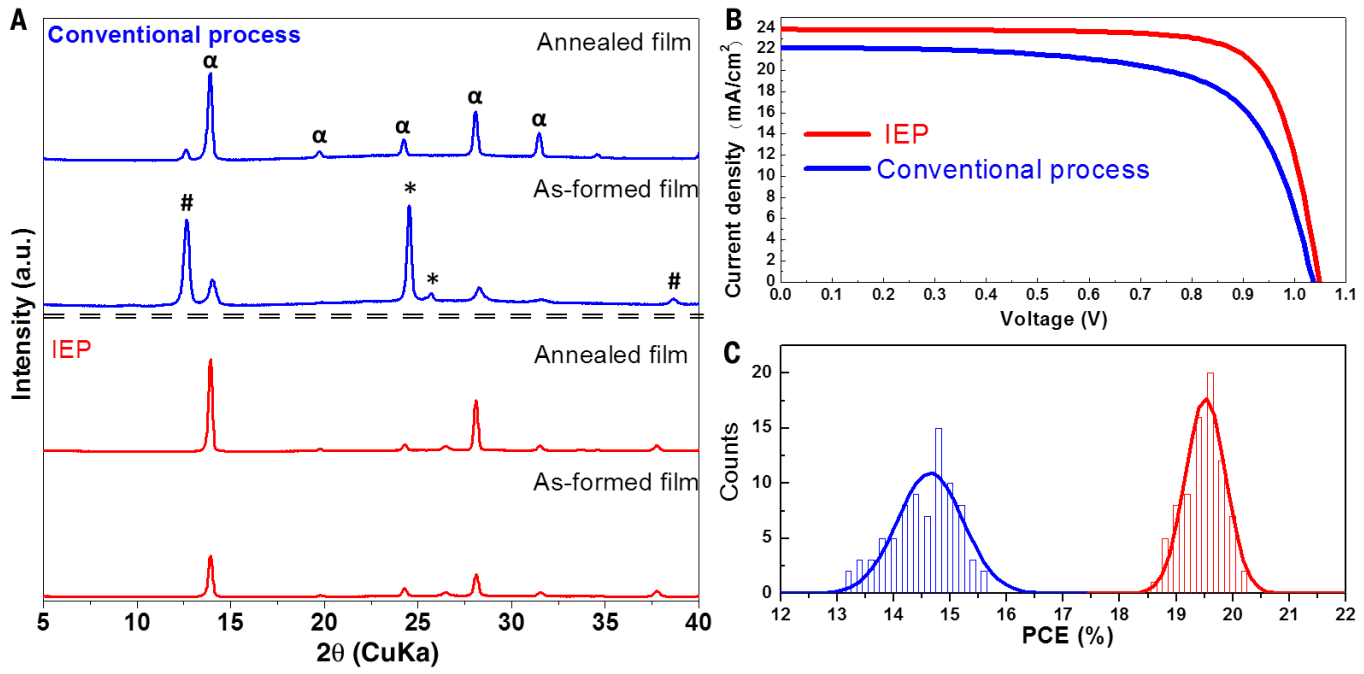

Fig. 3. Comparison of X-ray diffractions, performance, and reproducibility between IEP and conventional process. (A) XRD patterns of as-formed and annealed film for $\mathrm{FAPbl}_{3}$-based layers formed by IEP (red line) and conventional (blue line) process. $\alpha$, \#, and * denote the identified diffraction peaks corresponding to the $\mathrm{FAPbl}_{3}$ perovskite phase, $\mathrm{Pbl}_{2}$, and $\mathrm{FAl}$, respectively. (B) Representative $J-V$ curves for $\mathrm{FAPbl}_{3}$-based cells fabricated by IEP and conventional process. (C) Histogram of solar cell efficiencies for each $66 \mathrm{FAPbl}_{3}$-based cells fabricated by IEP and conventional process. 
Table 1. Comparison of layer thickness before and after $\mathrm{FAPbI}_{3}$ phase is formed by conventional and intramolecular exchange process. The thin $\mathrm{PbI}_{2}$ and $\mathrm{PbI}_{2}(\mathrm{DMSO})$ layers were deposited on a fused quartz glass, and their layer thickness was measured by alpha-step IQ surface profiler.

\begin{tabular}{lcc}
\hline Method & Before & After \\
\hline Conventional process $\left(\mathrm{PbI}_{2}\right)$ & $290 \mathrm{~nm}$ & $570 \mathrm{~nm}$ \\
$\mathrm{IEP}\left(\mathrm{PbI}_{2}(\mathrm{DMSO})\right)$ & $510 \mathrm{~nm}$ & $560 \mathrm{~nm}$ \\
\hline
\end{tabular}

